\title{
Clarice: o espectro da falta no sopro insistente da escrita
}

\author{
Evaldo Balbino da Silva* \\ Universidade Federal de Minas Gerais
}

\section{O dis(curso) sobre si mesmo}

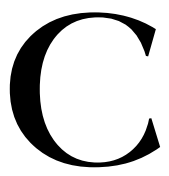

om o advento da pós-modernidade, o romance não narra mais uma história e, não tendo mais o que contar, acaba narrando a si próprio. Trata-se de uma crise de legitimação por que passa o mundo moderno e que tem a ver, na visão de Lyotard,

com a desestabilização do estatuto do conhecimento, com a incredulidade em relação ao sistema de representação da tradição filosófica e metafísica e com o descentramento da base das narrativas fundadoras (do mito ao épico e ao romance) que construíram o homem como sujeito e centro do universo. ${ }^{1}$

É no âmbito dessa desconstrução, porque nela se insere, que se localiza o lugar de Um sopro de vida, último livro de Clarice Lispector, escrito às vésperas da morte da autora. Essa obra, quebrando as rígidas distinções entre conto, romance ou novela, constrói-se como "uma escrita errante", no dizer de Benedito Nunes, porque nela a escritura se desenrola ao léu de múltiplos temas e motivos recorrentes (autoconhecimento, inquietação, expressão, morte etc.). Já sendo uma característica usual da autora, a reflexão sobre a linguagem substitui, na construção mesma do texto, o

\footnotetext{
* Doutorando em Literatura Comparada na FALE/UFMG.

${ }^{1}$ LYOTARD apud SCHMIDI, 1989. p. 215.
} 
desenvolvimento factual. Se isso é perceptível em todos os seus livros, em Um sopro de vida a ausência de fatos radicaliza-se mediante o espetáculo da voz na imediatez de sua produção, sem a interferência de um tempo-memória a produzir descontinuidade entre a voz e o discurso. "Este é um livro de não memórias. Passa-se agora mesmo, não importa quando foi ou é ou será esse agora mesmo" (p. 31). ${ }^{3}$

Dentre as reflexões que se fazem no livro, a mais presente, a mais personagem porque insistente, é a própria tarefa de escrever. Diluindo o tempo no agora do discurso, Um sopro de vida impõe um diálogo da escrita consigo mesma, por justamente voltar-se a todo momento para o próprio corpo do texto. Nesse voltar-se para si mesmo, o discurso clariciano coloca sob suspeita a palavra e se apresenta "como marginal a qualquer compreensão da literatura vista como representação da realidade", ${ }_{4}$ por justamente considerar o escrito como o próprio real. Sendo assim, é na tessitura do discurso que se constrói o significado, é nela que se constroem ou se subvertem as representações do mundo, já que o "que escrevo agora não é para ninguém: é diretamente para o próprio escrever, esse escrever consome o escrever. Este meu livro da noite me nutre de melodia cantabile. O que escrevo é autonomamente real" (p. 77).

Dentre as crises de valores dos últimos tempos, a linguagem também se abala e, ao contestar-se, questiona os próprios valores que a construíram. Voltando-se sobre si, numa constante tentativa de construção, a linguagem em Um sopro de vida considera as palavras como forças essenciais. Referindo-se ao livro, Bella Jozef afirma que nele "uma nova concepção da função da linguagem faz com que o significante se converta em função primordial na produção do sentido, com novas possibilidades de significação". 5

${ }^{2}$ NUNES, 1995. p. 13.

${ }^{3}$ As citações, extraídas do livro de CL, Um sopro de vida, serão indicadas pelas respectivas páginas em que se encontram. Utilizei a 1ํㅡㄹ edição, de 1978, feita pela Editora Nova Fronteira.

${ }^{4}$ FUKELMAN, 1988. p. 164.

${ }^{5}$ JOZEF, 1987. p. 76. 
Se por um lado é verdade que esse sopro de vida clariciano busca as palavras e dá a elas uma imensa importância para a construção do discurso, por outro não se pode dizer que ele, querendo a palavra em si, chega a fazer do seu texto uma "literatura do significante", uma vez que seu discurso não é suscitado pelo trabalho direto com a materialidade do signo, mas que antes se configura como "literatura do significado" levado ao extremo de sua fronteira, apontando sempre para um "referente volátil, a figuras de indizibilidade". Trata-se, então, de um encadeamento incessante de signos lingüísticos instaurado a contrapelo do discurso lógico. ${ }^{6}$

\section{Nas tranças do texto, os traços do corpo}

Texto quer dizer tecido; mas enquanto até aqui esse texto foi sempre tomado por um produto, por trás do qual se mantém mais ou menos oculto o sentido (a verdade), nós acentuamos no tecido a idéia gerativa de que um texto se faz, se trabalha através de um entrelaçamento perpétuo; perdido neste tecido - nessa textura - o sujeito se desfaz nele, qual uma aranha que se dissolve ela mesma nas secreções construtivas de sua teia. (Roland Barthes)

E se eu falar, que eu me permita ser descontínuo: não tenho compromisso comigo. Eu vou me acumulando, me acumulando - até que não caibo em mim e estouro em palavras. (Clarice Lispector - p. 69)

Ao abrirmos um livro que encerra um discurso literário, deparamo-nos com o espetáculo da linguagem. Não temos à nossa frente o autor do texto, mas uma escritura que, no dizer de Roland Barthes, é a destruição de toda a voz; é a inscrição de um corpo isento de identidade. ${ }^{7}$ Quem fala é a linguagem e não o autor. Entretanto, no fluxo verbal, nas imagens que se tecem na malha mesma do texto, emaranha-se uma voz que deseja. Há uma vontade, uma

\footnotetext{
${ }^{6}$ CAMPOS, 1992. p. 186.

7 BARTHES, 1984. p. 65.
} 
obsessão. Assim, das contorções da linguagem emerge um sujeito cuja concepção, ainda segundo Barthes, passa necessaria-mente pela psicanálise, já que a escritura é atravessada pelas pulsões inconscientes, ou seja, pelo próprio corpo do escritor que se inscreve no texto. A escritura não determina nem revela "um ser próprio, mas produz um sujeito em permanente mutação (ou, como diz Kristeva, um sujeito 'em processo')". ${ }^{8}$ O lugar do sujeito se constitui, portanto, pela fala. E é através dela que o sujeito clariciano se constrói e se define:

Eu, alquimista de mim mesmo. Sou um homem que se devora? Não, é que vivo em eterna mutação, com novas adaptações a meu renovado viver e nunca chego ao fim de cada um dos modos de existir. Vivo de esboços não acabados e vacilantes. Mas equilibrome como posso entre mim e eu, entre mim e os homens, entre mim e o Deus. (p. 85)

\title{
Nos fios da teia, os fiapos da falta
}

\begin{abstract}
"Escrever" existe por si mesmo? Não. É apenas o reflexo de uma coisa que pergunta. Eu trabalho com o inesperado. Escrevo como escrevo sem saber como e por quê - é por fatalidade de voz. O meu timbre sou eu. Escrever é uma indagação. É assim:?. (Clarice Lispector - p. 14)
\end{abstract}

Há de se verificar, em Um sopro de vida, que o discurso clariciano é engendrado por uma voz que se desliza excessivamente, pela repetição, através de um terreno escorregadio. São as palavras que, incessantemente, deslizam-se umas sobre as outras, perdendose e retomando-se a todo momento.

$\mathrm{Eu}, \mathrm{o}$ autor deste livro, estou sendo tomado por mil demônios que escrevem dentro de mim. Essa necessidade de fluir, ah, jamais, jamais parar de fluir. Se parar essa fonte que em cada um de nós existe é horrível. A fonte é de mistérios, mistérios escondidos e se parar é porque vem a morte. Tento neste livro meio doido, meio

\footnotetext{
${ }^{8}$ PERRONE-MOYSÉS, 1990. p. 46.
} 
farfalhante, meio dançando nu pelas estradas, meio palhaço, meio bobo da corte do rei. Eu, o rei do sono, só sei dormir e comer, nada mais aprendi. Quanto ao resto, ladies e gentlemen, eu me calo. Só não conto qual é o segredo da vida porque ainda não aprendi. (p. 72 - grifos meus)

Leyla Perrone-Moysés, tentando definir a escritura, diz que esse discurso que produz uma disseminação de sentidos, uma significação circulante, parece constituído para dizer algo, mas que na verdade ele só é feito para dizer dele mesmo, já que escrever é um ato intransitivo. Poderíamos, então, em Um sopro de vida, verificar na dança, nesse volteio de palavras nuas pelas estradas, alguma gratuidade? Seria plausível constatarmos que as palavras, doidas e farfalhantes, revolvem-se a todo momento e não deixam marcas pelo caminho, se a todo instante seus rumores e seus toques insistentes no papel vão traçando cicatrizes? Se a palavra não pára de se escrever, se ela insiste em jorrar dessa fonte cheia de mistérios que, diz-nos o narrador-autor de Clarice Lispector, há em nós e, ainda, se o fim dessa fonte leva à morte, é porque o discurso busca algo, a continuidade, a não-morte: "Eu escrevo como se fosse para salvar a vida de alguém. Provavelmente a minha própria vida" (p. 11). Ele procura por diversas vias atingir um alvo, conhecê-lo, dominá-lo: "Minha vida é tentar a conquista daquele Desconhecido. Porque Deus é de outro mundo - o grande fantasma" (p. 75).

Ser gratuito na construção da escritura é, pois, abrir as portas ao espetáculo da linguagem, apontar para a primeiridade desta, deixando o palco livre para que a palavra, grande e primeira atriz, encene e ludibrie. No entanto há outros atores pelos cantos do palco, a história, o mundo, para os quais a palavra sempre olha e aponta. Mas ainda há mais. Existe algo que se esconde, um rumor incessante, um fantasma, um ator que nunca falta nos bastidores. E sabemos dele porque sua sombra, projetada no palco pelas luzes estonteantes da palavra, desdobra-se em várias formas e nos chega deformada, inconcluída, misteriosa. É dessa fonte inesgotável, cheia

9 PERRONE-MOYSÉS, 1990. p. 38. 
de mistérios, desse desconhecimento de algo, que nascem os desejos. E o texto, movido por esses desejos, vai se tecendo, uma tessitura em processo, um tecido não acabado em cujas malhas encena uma perda, aquilo que falta ao sujeito:

Eu queria um modo de escrever delicadíssimo, esquizóide, esquivo verdadeiro que me revelasse a mim mesmo a face sem rugas da eternidade. Obcecado pelo desejo de ser feliz eu perdi minha vida. Movi-me com uma tensão de arco e flecha numa irrealidade de desejos (p. 88-89).

\section{A insistente tentativa de superação do nada (uma questão de estilo)}

Em Um sopro de vida o sujeito é escritor e deseja. Ele escreve para existir e sentir-se existente, constituindo pela fala um lugar para si no mundo. É criando Ângela, uma personagem, que o narradorautor julga tornar-se eterno, pois "depois que eu morrer, Ângela continuará a vibrar" (p. 24). Assim, por meio da escrita o sujeito pode, ilusoriamente, "preencher sua falta além da vida, alimentar a existência para além da morte. Através da obra poderá insuflar de vida e sentido o nome próprio". ${ }^{10} \mathrm{E}$, ainda, é através da personagem criada, da invenção de uma própria realidade, que o sujeito clariciano procura se salvar, "porque eu sozinho não consigo: a solidão, a mesma que existe em cada um, me faz inventar. E haverá outro modo de salvar-se? senão o de criar as próprias realidades?” (p. 18).

É considerando o processo da invenção por um "escritor criativo", que Freud compara o trabalho deste com as brincadeiras de uma criança. Esta, assim como aquele, "reajusta os elementos de seu mundo de uma nova forma que lhe agrade..." 11 Por isso constatamos na produção de um escritor aquilo que de infantil pode haver, o fantasiar, pois o que faz o mesmo senão brincar com as

\footnotetext{
${ }^{10}$ VIANNA, 1994. p. 304.

${ }^{11}$ FREUD, 1908. p. 149.
} 
palavras e, a partir delas e com elas, construir representações, outras realidades, que nos ludibriam a todo momento? Há, então, uma continuidade, o infantil que constantemente se manifesta de várias formas no adulto, e que diz de um desejo desencadeado por uma insatisfação. Na realidade, continua Freud,

nunca renunciamos a nada; apenas trocamos uma coisa por outra. O que parece ser uma renúncia é, na verdade, a formação de um substituto ou sub-rogado. (...) A criança, em vez de brincar, ela agora fantasia. Constrói castelos no ar e cria o que chamamos de devaneios. ${ }^{12}$

O sujeito, dentre os castelos que ergue numa tentativa inconsciente, tem o mundo simbólico como uma das vias para se buscar o tamponamento dessa falta que o persegue. No entanto, mesmo fazendo-se palavra, o desejo de completude é inatingível e, assim, desdobra-se numa demanda, numa escrita cujo fluxo é incessante e em que se detectam encenações da impossibilidade de superação de uma perda. Como corolário, representa-se sempre uma incompletude do sujeito.

Dessa escrita que não cessa, e que se registra sempre numa constante revolução da língua, emerge o estilo, o qual, no dizer de Roland Barthes, "só pode ser visto no plural do texto". ${ }^{13} \mathrm{O}$ estilo, nessa concepção, constrói-se ao longo da escrita, através de constantes atualizações de um sujeito incompleto que, por sua vez, estará sempre tentando, pela linguagem, completar-se. Trata-se, portanto, de uma insistente retomada, no jogo com os significantes, buscandose tamponar uma falta que existe e que se adere inexoravelmente ao sujeito. Essa falta nos diz do "fantasma fundamental do sujeito", o infantil que já se estrutura em sua infância e que nele permanece. Nessa acepção, o conceito de estilo passa inevitavelmente pela insistência, na escrita, desse fantasmático/infantil..$^{14}$

\footnotetext{
12 FREUD, 1908. p. 151.

${ }^{13}$ BARTHES, [s.d.]. p. 142.

${ }^{14}$ Para ver o desenvolvimento desta concepção de estilo, conferir: PERES, 1995.
} 
Assim, pois, para o sujeito em Clarice Lispector, aquele que cria "outras realidades", revolver as palavras é mexer no que está oculto, já que "tenho medo de escrever. É tão perigoso. Quem tentou, sabe. Perigo de mexer no que está oculto - e o mundo não está à tona, está oculto em suas raízes submersas em profundidades do mar" (p. 13). Escrever, ainda, é sugerir, aludir, pois "eu escrevo por intermédio de palavras que ocultam outras - as verdadeiras. É que as verdadeiras não podem ser denominadas. Mesmo que eu não saiba quais são as 'verdadeiras palavras', eu estou sempre aludindo a elas" (p. 72).

Por não se conhecerem as "verdadeiras palavras", o discurso, o fluxo verbal insistente, fica sempre à beira de dizer o indizivel, mas sem nunca dizê-lo, pois o que se diz escapa à voz: "O que está escrito aqui, meu ou de Ângela, são restos de uma demolição de alma, são cortes laterais de uma realidade que se me foge continuamente" (p. 19). Apesar dessa realidade que foge, que se esvai nas malhas de um texto ansioso - "Sou um escritor enredado e perdido. Escrever é difícil porque toca nas raias do impossível" (p. 62) -, o discurso não cessa de buscar uma verdade e insiste - "Eu quero a tua verdade, Ângela! Apenas isto: a tua verdade que não consigo captar" (p. 64) -, desdobrando-se em repetidas perguntas que não se respondem e que desencadeiam outras indagações:

Eu te procurei em dicionários e não encontrei teu significado. Onde está teu sinônimo no mundo? onde está o meu sinônimo na vida? Sou ímpar(p. 65); Qual é a palavra que representa o "desconhecido" que sentimos em nós mesmos? Há muito que já aderi ao desconhecido. Qual é a realidade do mundo? (p. 86).

Mesmo buscando essa realidade, querendo atingi-la como que na iminência de atingir o Paraíso perdido, o sujeito é tomado pelo medo, pelo estranhamento que a mesma realidade tão desejada lhe causa. O narrador-autor de Clarice cria Ângela, a outra realidade, o devaneio; e tenta entendê-la, possuí-la, mas

tentar possuir Ângela é como tentar desesperadamente agarrar no espelho o reflexo de uma rosa. No entanto bastava eu ficar de costa para o espelho e teria a rosa de per si. Mas aí entra o frígido medo de ser dono de uma realidade estranha e delicada de uma flor (p. 44). 
A "realidade estranha e delicada de uma flor" está do outro lado, no inverso de tudo, na imagem invertida da palavra. Mas o que tem o escritor são apenas as palavras, o seu limiar. Portanto, cabe ao escritor, não a responsabilidade de ultrapassar as linhas do impossível, mas, para ele, como bem aponta Barthes, "a verdadeira responsabilidade é a de suportar a literatura como compromisso falhado, como um olhar de Moisés sobre a Terra Prometida do real...". ${ }^{15}$ Por isso que "Deus me perdoe", pois

creio que estou divagando sobre o nada. Mas uma coisa eu tenho certeza, esse nada é o melhor personagem de um romance. Nesse vácuo do nada inserem-se fatos e coisas. O que se vê nesse modo de tornar tudo absolutamente do estado presente, o resultado não é mental: é uma forma muda de sentir absolutamente intraduzível por palavras. (p. 124)

\section{Referências Bibliográficas}

BARTHES, Roland. A morte do autor. In: O rumor da língua. São Paulo: Brasiliense, 1984.

BARTHES, Roland. Aula. 6. ed. São Paulo: Cultrix, 1992.

BARTHES, Roland. Escritores e escreventes. In: Ensaios críticos. Trad. Antônio Marrano e Isabel Pascoal. Lisboa: Edições 70, 1977, p. 205-215.

BARTHES, Roland. O estilo e sua imagem. In: . O rumor da língua. São Paulo: Brasiliense, 1984.

BARTHES, Roland. O que é a escritura? In: O grau zero da escritura. 3. ed. Trad. Anna Arnichand e Álvaro Lorencini. São Paulo: Cultrix, [s.d.].

CAMPOS, Haroldo de. Introdução à escritura de Clarice Lispector. In: Metalinguagem e outras metas: ensaios de teoria e crítica literária. São Paulo: Perspectiva, 1992.

${ }^{15}$ BARTHES, 1977. p. 209. 
FUKELMAN, Clarice. Uma palavra em exílio: uma leitura de Clarice Lispector. [s.1.]: [s.n.], 1988, p. 161-170.

FREUD, Sigmund. Escritores criativos e devaneio. [s.1.]: [s.n.], [s.d.].

JOZEF, Bella. Clarice Lispector - a recuperação da palavra poética. MUZART, Zahidé L. (Org.). Travessia, Florianópolis, n. 14, p. 63-80, 1. sem. 1987.

LISPECTOR, Clarice. Um sopro de vida: pulsações. Rio de Janeiro: Nova Fronteira, 1978.

NUNES, Benedito. O drama da linguagem: uma leitura de Clarice Lispector. São Paulo: Ática, 1995.

PERES, Ana Maria Clark. O infantil na literatura: uma questão de estilo. 1995. Tese (Doutorado em Literatura Comparada) - Faculdade de Letras da UFMG, Belo Horizonte.

PERRONE-MOYSÉS, Leyla. Crítica e escritura. In: Texto, crítica, escritura. São Paulo: Companhia das Letras, 1990, p. 35-57.

SCHMIDT, Rita Terezinha. A modernidade e o feminino na pulsação do discurso. In: A mulher na literatura. v. III, 1989.

VIANNA, Lúcia Helena. Clarice e o lugar do autor. In: A mulhere a literatura, 1994, p. 299-306.

\section{Resumo}

Este artigo busca, numa leitura de Um sopro de vida, livro póstumo de Clarice Lispector, discutir o conceito de escritura e o conceito de estilo, tomando-se por base alguns pressupostos da psicanálise.

\section{Resumen}

Este artículo busca, haciendo una lectura de Um sopro de vida, libro póstumo de Clarice Lispector, discutir los conceptos de escritura y de estilo, teniendo por base algunos presupuestos del psicoanálisis. 